\title{
MÁS ALLÁ DE LO HUMANO Y LO ANIMAL: UNA LECTURA COSMOPOLÍTICA DE "MEU TIO IAUARETÊ" (1969)
}

\author{
Nicolás Román \\ Universidad Andrés Bello \\ Santiago, Chile \\ nicolas.roman@unab.cl
}

RESUMEN / ABTRACT

\begin{abstract}
El cuento "Meu tío iauaretê" relata una transformación corporal de lo humano a lo animal que activa un cruce de identidades en relación con la naturaleza, la cultura, el lenguaje y la política. A partir de esa transformación proponemos una lectura que deconstruye la posición de lo humano en relación con lo animal. Las consecuencias de esa acción transforman el lenguaje, las relaciones políticas y crean una nueva comunidad. El devenir animal en esta lectura desafía las formas de administración de la vida, basada en la biopolítica, y propone una relación cosmopolítica (Viveiros de Castro, Metafísicas caníbales), en que el conjunto de lo viviente construye una relación de alianzas que resisten la máquina antropogénica.
\end{abstract}

Palabras clave: Guimarães Rosa, biopolítica, cosmopolítica, devenir animal.

\section{BEYOND HUMAN AND ANIMAL: A COSMOPOLITIC READING OF “MEU TIO IAUARETEे” (1969)}

\begin{abstract}
"Meu tí iauaretê" relates a story about a human which turns into an animal. This transformation shows an identity crossover between Nature, Culture, Language and Politics. Based on this, we propose a reading which consists in deconstruct the human state in front of the animal. The consequences of this transformation changes language, politics and make a new sense of community. Becoming animal in this reading defies the Biopolitics as the set of rules over life. As results of this challenge this situation proposes a Cosmopolitical relationship (Viveiros de Castro, Metafisicas canibales) between different living beings through the alliance, which resists the anthropogenic machine.
\end{abstract}

KEYWORDS: Guimarães Rosa, biopolitics, cosmopolitics, becoming animal. 
El monstruo es la posibilidad de la metamorfosis, de la transformación, es la potencia de la vida.

Ontologías de la monstruosidad

Andrea Torrano

La metamorfosis no es un proceso, "no era todavía" un proceso y "no será jamás" un proceso; la metamorfosis es anterior y exterior al proceso del proceso, es una figura (una figuración) del devenir.

Metafisicas caníbales

Eduardo Viveiros de Castro

El siguiente texto hace una lectura del cuento de Guimarães Rosa, "Meu tío iauretê", desde la perspectiva de las Metafísicas caníbales del antropólogo brasileño Eduardo Viveiros de Castro. El objetivo de esta lectura es deconstruir la figura de lo humano en vínculo con lo animal con el propósito de descubrir acciones que descentran al antropocentrismo. Bajo esa mirada, nos enfrentamos al texto leyendo tramas de oposiciones y asociaciones que forman nuevas retóricas políticas. Sus resultados en la textualidad descomponen los marcos humanos de la cultura y persiguen la superación de los binarismos por medio de la formación de un nuevo pueblo -iauretama, pueblo de jaguares- que descompone las lógicas políticas del pensamiento humanista. Esta escena literaria destaca los conflictos fronterizos debido a los avances de las líneas de explotación de la naturaleza, aparejado, de la colonización que hace invisible las redes y formas de existencias previa al avance de la modernización.

El cuento "Meu tio iauretê"/ "Mi tío jaguareté" (1969), de Guimarães Rosa se sitúa en un conflicto relacionado con diferentes tipos de límites. Esta situación confusa para la lectura se resuelve en la representación del cruce de la identidad entre un ser humano y los animales de la selva. En virtud de ese problema, el cuento pone en juego la imaginación con diversos tipos de oposiciones puestas en crisis. Estas tensiones se sitúan entre la civilización y la barbarie, la naturaleza y la cultura, además de explorar los límites de la palabra y los ruidos de la naturaleza. A partir de ese repertorio de temas buscamos en los archivos de la cultura una lectura donde estos elementos exponen una pluralidad de voces que traspasan los binarismos por medio de la configuración de una multiplicidad que cruza los límites de la identidad.

Aquellas oposiciones binarias en crisis son relaciones de las que demandamos leer una multiplicidad para poner en riesgo los conjuntos de 
identidades fijas y excluyentes, e. g., humanos versus animales. Este relato, por medio de la transformación corporal y afectiva de su protagonista, hace un giro en dirección de combinaciones sin una ontología definida que desafía las identidades estables, esenciales y específicas, este texto se sitúa en una dimensión común e inespecífica, definida por Florencia Garramuño del siguiente modo, "Se trata más bien de una indistinción entre aquello que nombra al animal y aquello que designa lo humano, una suerte de equivalencia e intercambiabilidad entre palabras, nombres y acciones que podrían definir lo humano o lo animal de modo indistinto" (121). Esta condición inespecífica es el desafío de abrir aquellas categorías cerradas de la ontología con una propuesta transformadora basada en la identidad del protagonista que se baraja entre lo humano y lo animal. La política de esta indistinción genera un colectivo nuevo que extrae sus elementos de una zona común de indistinción, justamente, de los espacios donde los humanos se vuelven animales en un contacto descrito por la escritura donde la cultura se contagia con la naturaleza.

Este cuento de Guimarães Rosa tiene diversos personajes: los tigreros ${ }^{1}$, los jaguares, los negros, los blancos y los indios. Ellos implican una diversidad de relaciones sociales a las que se suma el contacto de lenguas como el tupí y el portugués en el cuento. También hay encuentros del lenguaje de los humanos con la propuesta de un lenguaje de los animales, ahí hay una metamorfosis. Sin embargo, ante esta situación el cuento nos propone un desenlace fatal que expone la imposibilidad de traducibilidad de las experiencias de lo múltiple y su asimilación al lenguaje corriente. Esto provoca la acción de los dispositivos biopolíticos de persecución, que conciben la vida como un bien para ser resguardado bajo el techo de la máquina antropogénica, por lo tanto, la seguridad de esa vida política humana elimina como resto aquella vida animal.

Más allá del desenlace de la narración, la asociación entre humanos y animales implica la implosión y la crisis del vocabulario de la política

En este caso optamos por la designación de tigrero debido a que trabajamos con esta acepción para designar al personaje encargado de la eliminación de los jaguares. La designación tigre en oposición a la traducción de onça aceptado en español como onza, pero de poco uso en el español de Chile, aunque muy relevante en el texto al ser utilizado como verbo de la transformación: eu onçeí. Es destacable la inestabilidad poscolonial de los signos: "jaguar-iauaretê-onza-tigre" incluida en el archivo colonial y los animales que lo habitan, tal como ocurre en la lectura de González Echeverría sobre Facundo Quiroga, como el tigre de los llanos, en la escritura sarmentina. 
de categorías y alianzas cerradas, establecidas entre la connotación de un amigo y un enemigo, como formas de identidad y alteridad. Esta operación en el texto es enfrentada a complejos cosmopolíticos y alianzas múltiples. Sus expresiones van más allá del eje de la identidad que define lo humano sobre la base del lenguaje articulado, en otras palabras, buscamos una lectura política más allá del signo de lo humano, apostamos por la transformación del cuerpo en un devenir animal.

Por último, en el análisis de este viraje, el mismísimo ejercicio de la narración es puesto en crisis por medio de la exposición de un pueblo porvenir, la belleza de un pueblo que adviene en el presente y que se extingue en el ejercicio fugaz de la lectura. La narración como género discursivo cobra así un lugar central como representación y creación de un complejo de fuerzas múltiples descrito en la selva como un emplazamiento cultural que resiste una doxa de carácter humanista.

Este relato no trata solamente de acercarse al espacio fronterizo de la selva, límite de la explotación agrícola -donde los tigreros resguardan el cosmos de la fazenda para la explotación capitalista- más queremos leer este relato en relación con esos límites de manera crítica. Primero, queremos caracterizar los elementos de la frontera que separa lo humano y lo animal como formas de lo viviente. Segundo, traspasar este límite excluyente propone una alteración de las condiciones de la política debido a que rompe la división entre el bios y la zoé, entendida como la vida humana y la vida animal. De ese modo, el relato antes que proponer una biopolítica -la administración de la vida en la polis-, presenta una cosmopolítica de un pueblo por/venir establecido en el vínculo incluyente de humanos y animales. Tercero, en esa relación se muestra la organización de la sobrevivencia de un pueblo, cuyas contradicciones lo exponen a la clausura de su nueva forma de alianzas, la sobrevivencia es un más allá de la vida, un exceso, pero también es un resto de la vida, la de aquellos que son sobrevivientes.

\section{LOS PROBLEMAS DE LA PALABRA}

Este texto de Guimarães Rosa ha sido analizado en el cruce de lenguas que construye una nueva representación y una nueva expresión del lenguaje. La versatilidad de la lengua del cuento se basa en el uso del portugués mezclado con el tupí y con un fuerte componente de oralidad en la escritura. La representación de este cuento no solo hace un uso específico del lenguaje, sino que cruza la 
humanidad, la indianidad y la animalidad en una mezcla que no se resuelve en un mestizaje cultural, sino que en una propuesta inespecífica de contactos de lo humano y lo animal en los bordes civilizatorios representados por el protagonista del texto, su interacción con los animales y la propia lengua es el medio de esto traspasos.

La palabra escrita entremezclada con la oralidad y derruida por las onomatopeyas animales que pronuncia el protagonista producen un efecto novedoso y significativo en la representación. Los críticos han analizado el enriquecimiento de la tradición literaria latinoamericana en este texto sobre la base de los elementos de la lengua y su tratamiento. Rosa para Haroldo de Campos establece de este modo: "Sua revolução da palabra, e consigue fazer dela um problema novo, autónoma, alimentado em latencias e possibilidades peculiares a nossa lingua" (3). La riqueza del cuento se articula específicamente en la lengua del relato construida entre el tupí y la oralidad que, junto con las onomatopeyas felinas, ofrecen una expresión compartida por humanos y animales, esfera donde el narrador se inscribe para producir su propio relato. El primer elemento, la lengua indígena tupí es uno de los aportes concretos del relato en las modificaciones narrativas, sobre todo al final del texto, en las últimas palabras pronunciadas por el protagonista, "As derradeiras enunciações deste se contaminam fortemente pelo idioma indígena e se desarticulam racionalmente" (Perrone 765). El cuento muestra un contacto y un contagio identitario expresado a través de estas modificaciones que muestran una geografía interna donde se intercambia un habla metropolitana, el portugués, con una lengua indígena, el tupí.

El contacto entre escritura y oralidad construye una representación que gira sobre ejes más allá de los tradicionales, más allá del canon de la lengua,

[n]esse texto de Rosa, além de sus costumeiras praticas de deformação oral e renovação do acervo da lingua (frecuentemente à base de matrices arcaicas ou classicas injetadas de sorprendente vitalidades) um procedimento prevalece, com função não apenas estilísticas mas fabulativa: a tupinização, a intervalos, da linguagem. (de Campos 3)

La tupinización de la lengua contribuye a la dimensión narrativa del texto, su fábula está enmarcada en ese devenir indígena que se transforma en devenir animal. Lo fundamental de esta estrategia narrativa es rebasar los bordes de la experimentación formal y construir un texto, cuyo contenido necesita estos materiales para denotar la complejidad de esta ficción. Estos recursos lingüísticos abren los cierres de las sintaxis realistas -“Ao nível da 
manipulação lingüística, a ficcão rossiana é mais atual, menos comprometida com o pasado, com assim dito romance burgués do século 19, que o "nouveau roman" francês" (De Campos 3)-. Esta escritura se opone a las reglas de una gramática específica, "Rosa, para fazer um texto sem límites, do ponto de vista do alcance do texto, escreve fora do cânone da lingua, já que este é limitador e escravizador do que necessita ser escrito. O processo então é servir-se (ativamente) do polilingüismo em sua própria língua" (Imbroisi y Scorilack 71). El uso de esta pluralidad de lenguas, y en algunos casos de formas no lingüísticas, pasa de una realidad de la lengua al ámbito de la cultura. Las tensiones de la lengua, como ha señalado la crítica al respecto de este texto, refuerzan la idea del lenguaje asociado a una realidad cultural diversa y en conflicto, donde la función de la escritura toma el rol de la mediación cultural. Gabriela Reinaldo lee esta operación como una forma de antropofagia, como una forma de relación con la alteridad construida a partir de un procesos de asimilación compleja, "digestão lenta, elaborada, referencia de um sertão de permanencia, traduz índio, branco, negro, onça, tupi, onomatopéia, numa síntese digestivo literaria" (Reinaldo 272). El plurilingüismo, en paralelo, construye una relación con la cultura basada en una asimilación antropofágica que implica una "interiorização de Outro [que] é inseparável da exteriorização do Eu" (Cernicchiaro 96), por ende, con esta operación de digestión, en esta maceración de la cultura, se establece un contacto intenso -salir de sí para entrar en otro- en una abolición de elementos dicotómicos que pasan de la lengua a la cultura y a la identidad.

El plurilingüismo describe el devenir de la identidad del protagonista en el cuento. Su uso de la lengua describe la construcción de su identidad. Este proceso de asimilación realizado en el texto, descrito anteriormente en clave antropofágica como metáfora de codificación cultural, es una operación que justamente describe las interacciones del pensamiento cosmopolítico amerindio con el texto. Queremos afirmar que en esa revolución -según Haroldo de Campos- la lengua portuguesa también padece una lenta devoración cultural (Gabriela Reinaldo) que se nutre de perspectivas antropofágicas amerindias como metáforas conceptuales de las operaciones culturales en el texto. Esta asimilación digestiva involucra la metafísica de la predación señalada por Eduardo Viveiros de Castro, en este contexto antropofágico, "el yo está determinado en cuanto otro por el acto de incorporación de ese otro, que a su vez se convierte en un yo, pero siempre en el otro, literalmente a través del otro" (Viveiros de Castro, Metafisicas... 143). La combinatoria identitaria expresada por el lenguaje se conecta con un sistema de pensamiento que 
reconoce en la alteridad la fuente de la identidad, "la antropofagia como antropología" (144), señala Eduardo Viveiros de Castro, es un cuadro donde la construcción identitaria es inespecífica, no se fija en un yo aislado autocontenido, sino que se exterioriza en la búsqueda de lo impropio, así la impropiedad es un lugar de pertenencia en la pérdida del nombre.

\section{LOS PROBLEMAS DEL NOMBRE PROPIO}

La narración de "Meu teu Iauareté" narra el encuentro entre un tigrero, el protagonista y narrador en primera persona del relato, y un viajero en posición de narratario. Esto ocurre en un lugar remoto, en una fazenda, donde el personaje principal trabajaba en el exterminio de jaguares. A medida que se desarrolla este encuentro se narra en primera persona la vida del personaje en un lenguaje atravesado por expresiones en portugués, en tupí y onomatopeyas que hacen mutar las palabras del lenguaje articulado al ruido animal. El motivo central del cuento es que el personaje principal mantiene vínculos de parentesco y alianza con los jaguares que habitan la selva, esto en virtud de que el tío del tigrero es un animal, un jaguar. Esta alianza va más allá, debido a que el protagonista ha elegido como pareja amorosa a una felina de la selva, el jaguar María-María.

La trama cuenta los orígenes del personaje, él relata sobre su madre india y su padre blanco- hasta llegar al presente en su trabajo de tigrero (onçeiro). En ese momento, este hombre ha renunciado a esta última labor debido a que está enamorado de un jaguar hembra. Por medio de esa alianza él se reconoce como parte de los jaguares y reivindica que tiene un tío animal, un tío materno que por vía de filiación india le había heredado el elemento felino a su condición humana.

En el relato, a medida que el narrador descubre su historia al viajero, muestra cómo él ha asimilado esta filiación humano-animal, él comienza por redefinir su origen y destaca su relación con el tío jaguar. Además, el narrador en la soledad selvática termina por convivir con los felinos, se reconoce como uno más de ellos, "Yo soy jaguar. El jaguareté mi tío, hermano de mi madre, tutira... ¡Mis parientes! ¡Mis parientes!” (436). Esta expresión de pertenencia, comunicada por medio de una oración que desvía la gramática de su uso normativo y cuya sintaxis atropella la rigidez del lenguaje, muestra la filiación cultural y natural que está redefiniendo al protagonista por medio de la alianza con sus parientes animales. 
El narrador, sobre la base de ese vínculo, expresa que ha perdido su nombre propio humano. Él se ha despojado de su identidad luego de transitar por distintos nombres, "Mi padre me llevó al misionero. Me bautizó, me bautizó. Nombre de Toñito; bonito, ¿será? Antonio de Jesús... Después me llamaban Macuncozo, nombre de un rancho de otro dueño, sí - un rancho que llaman Macuncozo... Ahora no tengo ningún nombre, no lo necesito" (435). La pérdida del nombre propio se debe a su futilidad y a la nueva inscripción del sujeto en un cuadro de relaciones que redefinen su enunciación: entre lo animal y lo cultural. El protagonista hijo de india, toma un nombre de cristiano, luego el nombre del dueño de su fuerza de trabajo y, por último, olvida su nombre en el medio selvático que lo acoge.

El narrador, en un acto de confesión, hace un viraje de su identidad hacia su relación con la multiplicidad, sus palabras y sus acciones son enunciadas desde otro lugar, "esto es ianaretama, tierra de jaguares" (430). Particularmente, la "tierra de jaguares", designada como iauaretama, se establece como una comunidad de felinos a partir de la cual el narrador compone el lugar de su enunciación, donde se despoja finalmente de su nombre propio debido a su pertenencia al espacio de lo múltiple de la metamorfosis.

El lenguaje del cuento es el testimonio de aquella metamorfosis, muestra el proceso de aquel devenir animal. Las palabras en transformación del texto pasan de una lengua a otra, cruzan onomatopeyas, palabras en portugués, neologismos y palabras indias, podríamos pensar que este es un intento por tensar la estructura del portugués como una lengua nacional puesta en el flujo de un devenir. Las palabras con que el tigrero relata su propia historia son "Interjeições e outros ruídos aparentemente sem sentido [que] passam então transformar a fala do onceiro até o ponto limite em que se entende que ele sofre uma metamorfose" (Soares 2). El lenguaje de la narración se forma como un lenguaje impropio, como una lengua singular que se sitúa en el cruce de afectos humanos y animales; esta lengua describe la transformación de la alianza que tiene el protagonista y los jaguares. Su alianza y su vínculo no pasan por ejercer un puente entre lo humano y lo animal, sino que la metamorfosis de su identidad es la mezcla indistinta de esos extremos que se confunden y no se dejan definir, asimismo, como si quisiéramos definir su lengua, la lengua del narrador deviene otra en su metamorfosis.

La narración se sitúa en esa encrucijada donde se desploman las identidades estables y esenciales, por lo tanto, el relato nos enfrenta con un problema central: “crear una lengua que diese cuenta del lugar 'imposible' en el que coloca a su personaje, de esa experiencia de desubjetivación” (Yelin 230). El relato 
implica una búsqueda formal relacionada con la condición lingüísticamente inestable que tiene la experiencia del narrador. Esta condición no tiene una gramática, por este motivo, "linguagem se vê obrigada a incorporar elementos que nos parecem vir de fora da própria língua, elementos que, sendo expressão da animalidade e, portanto, de uma alteridade radical, seriam tão estranhos à própria língua que a coloca em risco, o risco de ser ela também devorada e não fazer mais sentido" (Soares 3). El lenguaje pierde su forma humana en la conjunción entre animal y lengua. Este lenguaje animalizado crea una continuidad significante, en este los signos han dejado de establecer sus recortes arbitrarios sobre la base de la identidad y diferencia de una oposición binaria que otorga el valor lingüístico, como señala Saussure. La materialidad de los sonidos ha alterado la condición material de los signos, la compartimentación cerrada de los referentes de la lengua ha roto su cerrojo para relacionarse con una nueva totalidad significante en la que humano-animal -naturaleza y cultura- transponen sus fronteras, el lenguaje humano tiende a ser devorado por la lengua animal, de este modo, la lengua se fuerza a su condición material, a auscultar ese espacio de traductibilidad de la experiencia signada por la singularidad.

El experimento del lenguaje y esta condición animal no apuntan a un repertorio de elementos ancestrales ni conceptos fijos de la identidad, como si fuera una cuestión totémica-tampoco el animal trae consigo un sentido $a$ priori sobre la comunidad y el sujeto- mas esta condición busca señalar lo problemático de la segmentación entre las especies, las lenguas y los sonidos. El uso performativo del lenguaje demuestra una mezcla de lenguas, como lo señala Julieta Yelin,

Una de las más importantes es “¿Nhem?”, que, como señala Haroldo de Campos en su ensayo "A linguagem do iauaretê" (1992), envuelve un expletivo-indagativo " ¿Eh?”, pero que, como se va verificando, es antes un "¿Nhennhem?” (del tupí Nhehê o nheeng, que significa "hablar"). De hecho, Rosa lo utiliza en ese sentido cuando lo convierte en el verbo "nheengar" (“... em noite de lua incerta ele gritava bobagem, gritava, nheengava...") (Yelin 225).

El problema indicado se afinca en el cruce de una experiencia que cuestiona los fundamentos de una traducción unívoca, en el nivel de la lengua y afecta los términos de la cultura y la política. La expresión intraducible de este lenguaje-jaguar viene del experimento con los materiales significantes de una nueva relación para mostrar la identidad en transformación del narrador; 
“jaguanhenhém”, es el término usado por él para referir su lengua impropia construida a medio camino entre los animales y los humanos, la lengua de su tío jaguar y la lengua con la que sostiene su relación con María-María.

La inscripción cultural de estas expresiones no se puede definir. No se puede establecer la frontera entre ruido y lengua, entre sonido y palabra. Los sonidos de los que se rodea el protagonista son, en una perspectiva lingüística, el fondo del cual la lengua recorta su material significante, aunque para el narrador ese fondo indiferenciado, los ruidos, se transforman en interjecciones y onomatopeyas- estas expresiones pasan a ser figuras para la creación de su lengua. Esta relación entre ruido y palabra "demarca lo colectivo: el habla, entre lo audible y lo inaudible, de un grupo, de una multitud, una red, que oscila entre el puro ruido y un posible sentido" (Giorgi 148). En esa región de exploración se sitúa el texto, sus expresiones buscan indagar en la crisis y la expansión de las palabras en la formación de un sujeto y la configuración de un pueblo en la oscilación de lo audible y lo inaudible.

En esa dimensión, el habla colectiva del personaje en oposición a una lengua nacional dibuja una tensión política donde se afirma que "[e]l pueblo humilde resiste en el lenguaje mediante el dialecto, la jerga o el argot" (DidiHuberman 215). Por medio de estas formas menores de una lengua nacional, una lengua mayor en términos de Gilles Deleuze a propósito de Franz Kafka, la narración hace un ruido, genera una interferencia, usa las palabras como una forma de relación, no de representación ni de referencia. Estas palabras cargan con una resistencia, el uso de ellas se hace "en función de un pueblo futuro" (Deleuze, Conversaciones 229). Esta es una formación disruptiva de la lengua, el narrador evita la regularidad gramatical asociada con el orden y esboza la opacidad de un pueblo, en función de la multiplicidad que representa una comunidad de los jaguares asociados con un humano sin nombre propio.

Utilizar la lengua de esta manera presiona su estructura y la condiciona a una mezcla con el habla -con una forma de hablar particular-genera una discontinuidad entre la lengua, como el uso de una lengua nacional asociada con el Estado versus el habla de un pueblo sin Estado. De ese modo, el texto ilumina los dos sentidos del concepto de pueblo que está marcado "entre dos polos opuestos: por una parte, el conjunto del Pueblo como cuerpo político integral, por otra, el subconjunto pueblo como multiplicidad fragmentaria de cuerpos menesterosos y excluidos" (Agamben, Homo 226). Esta división replica la inscripción entre aquellos que son una pura vida, la zoé, del costado del animal mudo que emite solo ruidos, o bien, de aquellos humanos privados del ejercicio de la palabra, y, por otro, el bios, compuesto por aquellos 
animales políticos que tienen lenguaje como representación. "No es, pues, azar que un pasaje de la Política [de Aristóteles] sitúe el lugar de la Polis en el paso de la voz al lenguaje. El nexo entre nuda vida y política es el mismo que la definición metafísica del hombre como viviente que posee el lenguaje" (Agamben 17). Ese pueblo de los menesterosos y los excluidos en el cuento busca la expresión de su propia lengua para marcar la frontera en que se desagrega del conjunto de una lengua nacional, que en este caso es el portugués. Esta operación ilumina una tensión con la palabra del Estado y el canon, por su incapacidad de asir lo múltiple bajo una gramática normativa. Además, del lado de los que no tienen palabras están los animales, aquellos que son una mera vida desnuda, a la que el tigrero se integra al renunciar a su nombre propio.

$\mathrm{Al}$ asumir la condición impropia del animal mudo, el protagonista con la renuncia a su nombre humano ingresa en una condición común con el animal. Se inaugura así una comunidad no-idéntica entre el tigrero y los jaguares, que designa un pueblo por venir establecido en una relación inespecífica de la identidad, "Un pueblo por venir, que rompa con la línea temporal y tampoco se establezca mirando a un pasado anterior de linajes; un pueblo que sea, más bien, el de aquellos que no tienen pueblo (que no son masa, que no tienen un origen fijo, ni costumbres fijadas)" (Núñez 225). Bajo esta noción de Gilles Deleuze, "el pueblo por venir" indica aquella alianza de una potencia presente que no ha sido regularizada bajo una idea o un emblema en particular, "el pueblo por venir" destaca la virtualidad del pueblo, las nuevas posibilidades y expresiones de lo viviente que acoge en su seno, un pueblo que rompe con la línea del tiempo, tal como es señalado en el epígrafe de este trabajo. La transformación es un estado del tiempo, una forma de la ontología en transformación que no pasa de un estado a otro, sino que deviene un estado de la inmanencia del devenir, en palabras de Gilles Deleuze. Podemos agregar que el devenir está relacionado con la impersonalidad de la vida, de una existencia no dominada por el sujeto, no sometida a un mandato estricto de la identidad, solamente la vida: "La vida del individuo le cedió lugar a una vida impersonal, y sin embargo singular, de la que se desprende un puro acontecimiento liberado de los accidentes de la vida interior y exterior, es decir, de la subjetividad y de la objetividad de lo que pasa" (Deleuze, "La inmanencia..." 38).

La escucha y la comunicación de la narración se ve frustrada en el desenlace fatal del relato en que el narrador es abatido por su silente testigo que le dispara. El desenlace fatal del cuento señala el compromiso entre la 
representación y los dispositivos de poder en sus dimensiones tanatopolíticas de la ejecución de la diferencia.

La función de la representación carga consigo un poder gregario en que la palabra animal no encuentra su espacio en la imaginación, ya que, "[1]a policía de las imágenes aborrece al Otro al considerarlo como un rebaño ${ }^{2}$, y adora lo Mismo al constituirlo como tropa. Ve a los enemigos como jaurías animales que es preciso acorralar para su traslado al matadero" (Didi-Huberman 63). Por lo tanto, lo representable está asociado con una política de lo visible, basado en un cruce taxativo, animalizante y biopolítico que separa las vidas descartables de aquellas que merecen vivir, bajo la operación de hacer vivir/ dejar morir en la construcción de la identidad y la diferencia. La muerte del narrador asesinado por el viajero, oyente de la historia, marca esta diferencia entre una vida vivible y una sacrificable.

\section{BIOPOLÍTICA VERSUS COSMOPOLÍTICA}

En un panorama más general, esta escena literaria del cruce entre el poder de las armas y las letras inscribe sus secuencias en la literatura latinoamericana en función de una serie de lecturas relacionadas con el sacrificio del enemigo interno a causa de su diferencia animal. "Juan Darién", de Horacio Quiroga, se sitúa en aquella problemática biopolítica sobre quienes se deben dejar morir para que otros puedan vivir. Asimismo, las ficciones del enemigo interno, condenado a la muerte por tener una vida carente de sentido, se puede comprobar en El matadero de Esteban Echeverría, en Patas de perro de Carlos Droguett y, ejemplarmente, en "Meu tío iauareté" de Guimarães Rosa. En estos relatos, la función punitiva sobre la vida animal pone en juego dimensiones de la aplicación correctiva y biopolítica de un poder que, en tanto pastoral, debe ejecutar aquellos depredadores que agreden a los animales gregarios.

En esa disputa el tigre es el símil del lobo hobbesiano, también en el Facundo Sarmiento usa esa alteridad devoradora para referirse a Facundo Quiroga, su referencia es el tigre de los llanos encarnado por el gaucho, quien

2 En francés, el texto hace la oposición entre troupeau, rebaño-manada, y troupe, tropa-compañía. Didi-Huberman, Georges. Peuples exposés, peuples figurantes. L'oeil de l'histoire. Normandie: Les Éditions de Minuit, 2012. 
encarna la amenaza exterior. Por ende, se debe eliminar al hombre-animal porque representa la transformación interna del devenir del humano al animal, de homo a homini lupus.

Frente a ese cuadro, el cuento de Guimarães Rosa nos muestra el suplemento de sentido de la vida más allá de su uso en la polis que ofrece una integración: la vida animal como parte de la condición humana, que se resiste al tratamiento pastoral de la condición del sujeto. Esta otra política de orden afirmativo tiene una reflexión sobre la vida en común con la naturaleza como continuidad de lo viviente, esta no se circunscribe al polo no marcado como fondo de la condición humana, sino que se destaca para valorar prácticas de escritura que apuntan a la multiplicidad de lo vivo a partir de su relación con lo animal. En ese orden,

[1]a vida animal emerge como un campo expansivo, un nudo de la imaginación que deja leer un reordenamiento más vasto, reordenamiento que pasa por una desestabilización de la distancia-que frecuentemente se pensó en términos de una naturaleza y una ontología- entre humano y animal, y por la indagación de una nueva proximidad que es a la vez una zona de interrogación ética y un horizonte de politización (Giorgi 12).

La luz del animal expone la vida precaria del sujeto como un registro mezquino ante la diversidad y multiplicidad de lo viviente. Las zonas de contacto, más que marcar una división externa y excluyente entre el animal ajeno a la cultura y un humano externo a la naturaleza, apunta hacia una reconciliación con la animalidad enmudecida al alero del antropocentrismo.

En ese sentido, la poética de Guimarães Rosa, en "Meu tío iauareté", afirma "la metamorfosis continua del mundo natural, del cual no es ajeno el hombre, que es siempre una identidad precaria, inacabada" (Yelin 225). Por ende, esta visión interna de lo natural y lo animal en el hombre no es una contraofensiva reaccionaria antihumanista basada en el irracionalismo que utiliza al animal como un sustrato inmotivado situado en el fondo de lo natural no marcado, que reafirma la jerarquía humano y animal en función de la razón y la sinrazón del animal.

Por el contrario, la reflexión de esta transformación humana es un elemento dirigido hacia la multiplicidad y lo diverso de la cultura, lo humano y la condición natural. Este sería uno de los caminos para una posible reformulación de la biopolítica hacia una cosmopolítica, a partir de una reflexión sobre lo viviente en el sujeto que desajuste la situación de a(bando)no de la condición 
natural y animal. Se trata de reconocer en el animal una forma de vida y la relación con él una forma de lo político, como lo afirma el narrador del cuento: "Los jaguares, ellos también saben mucho. Hay cosas que él ve, y uno no ve, no puede. ¡Uh! Tantas cosas... no me gusta saber mucho, me da dolor de cabeza. Solo sé lo que el jaguar sabe. Pero de eso, lo sé todo" (420). El vínculo entre el narrador y los jaguares se hace intenso en esa proximidad, el narrador descubre el lugar de lo animal, no obstante, este saber queda bajo el resguardo del secreto, se convierte en algo conocido, pero no develado. En particular, este contacto íntimo entre los jaguares y el protagonista devela una inclinación de la narrativa de Rosa por lo viviente:

Guimarães Rosa não interessava apenas escrever sobre os animais, convertê-los em simples construtos literários, mas também procurou abordá-los como sujeitos dotados de sensibilidades, inteligência e conhecimentos sobre o mundo. Seu olhar sobre a outridade animal, como atestam inúmeras outras narrativas de su autoria, está atravessado por um compromisso ético e afetivo com esses viventes (Maciel 267).

El compromiso ético y afectivo no se basa en una visión asimétrica en relación con lo animal como una expresión inferior de la naturaleza en relación con lo humano, por el contrario, la forma de la vida de ese contacto muestra una interrogante por la interioridad animal de lo humano, por ese espacio que más que expulsar lo natural de la condición del sujeto lo acerca a la continuidad de lo vivo y sus saberes.

El narrador apunta a que la posición del jaguar en la selva detenta un conocimiento, este tiene una condición asignada en la que articula relaciones con otros animales y con el espacio. No porque el animal contenga en sí una visión natural y romántica, sino porque en la selva se organiza un mundo de comunicación que es posible percibir como un sistema. En un nivel básico existe una comunicación y señales que indican presencias e interacciones. Oír y oler, saber vivir en contacto, es entender estas formas de señalar. “¿Usté ya vio a las víboras? Así, pues. ¡Apé! Poranga suú, suú, jucá-iucá... A veces hace un ruidito, pirirí, en las hojas secas, cuando pisa ramitas, eh, eh -pajarito huye. La capivara grita, de lejos usté oye: ¡au!- y salta al agua, el jaguar ya está aquí” (419). En esa relación el narrador sabe dónde, cuándo y cómo va actuar un jaguar. El animal ha dejado de ser el polo no marcado de las relaciones entre naturaleza y cultura, en esta organización del saber el animal no es parte del fondo indiferenciado de lo natural, sino que pasa a ser un elemento significante dentro de la configuración del espacio; más 
aún, el protagonista es traspasado por el afecto del jaguar y lo transmite por medio de la narración,

Sabía lo que el jaguar estaba pensando. ¿Usted sabe en lo que piensa el jaguar? ¿No sabe? Eh, entonces aprenda: el jaguar solo piensa en una cosa-que todo es bonito, bueno, bonito, bueno, sin toparse con nada. Nada más piensa eso, todo el tiempo, largo, siempre lo mismo, y así va pensando mientras camina, come, duerme, haga lo que haga... Cuando algo malo ocurre, entonces de pronto chirría, ruge, tiene rabia, pero no piensa en nada: en ese instante deja de pensar (442-3).

La perspectiva del jaguar no tiene mal y no provoca daño, no hay actividad perjudicial para el otro, como indica Julieta Yelin, el animal no asesina para matar, sino que para comer. En ese orden, el narrador describe cuál es el comportamiento que se debe tener ante un jaguar, por supuesto, no debe ser el comportamiento de una presa, "Eh, hace falta saber mirar el jaguar, encarado, mirar con coraje, ha, él lo respeta. Si usté ve con miedo, él sabe, usté entonces está perdido. No puede tener miedo. El jaguar sabe quién es usté, sabe lo que está sintiendo" (424). Por esa razón, el miedo es uno de los motivos de la agresión y la desconfianza, el gatillo de la hostilidad. Romper el eje cazador-presa indica las posiciones de una ontología móvil.

Por otro lado, la poética del relato, en un nivel, se inclina por esa relación de comprensión hacia la alteridad, basada en la asignación de roles mutables. El animal se encuentra en una posición externa e interna. Afuera en tanto parte de lo natural, y adentro como parte del sujeto que deviene animal traspasado por esa condición. La narración nos propone, "la disolución de los límites entre hombre y animal -y la consecuente negación de la oposición entre ambos-mediante la construcción de imaginarios transicionales" (Yelin 225). El relato, en oposición de una domesticación del sujeto en función de la administración del bios que, en tanto biopolítica debe excluir a la zoé, propone una condición cosmopolítica que trae una reflexión sobre la vida y la naturaleza en una perspectiva sobre lo múltiple en que la dicotomía excluyente humano-animal no se busca destruir en función de una oposición, sino que se hace devenir en una transición, una inscripción de lo humano en la órbita animal. Porque esta parte "está ligada àquela dimensão do humano que este oculta, notadamente, ao desqualificar seu corpo, seus desejos ou seus afetos em relaçao ao seu espíritu e à sua racionalidade" (Lestel 37). Esta dimensión oculta, no inscrita en la racionalidad ni la capacidad del lenguaje, permite abrir un abanico de interacciones humano-animales en términos de simetría. 
Estas relaciones de los humanos y no humanos sin una exclusión, construidas sobra la base de una percepción de elementos en común se expresa en sistemas de pensamiento, principalmente amazónicos y amerindios, que "consiste[n] en pensar que los no humanos están provistos de un alma o de una consciencia idéntica a los no humanos pero que se distinguen unos de otros por cuerpos diferentes" (Descola 50). En función de esa identidad variable basada en la corporalidad, la naturaleza se vuelve múltiple en la medida que está poblada por diversos cuerpos y su ontología es constante, al decir de Viveiros de Castro, ya que la sustancia humana tiene que ver con diversos roles de agencia, esta condición implica una abolición del antropocentrismo, por ende, existen otros elementos en un tablero que determina la política de la naturaleza.

\section{LA COSMOPOLÍTICA}

El lenguaje del relato y las acciones en su interior, sobre todo la relación entre el narrador y el jaguar, describen esta interacción cosmopolítica que reordena la administración del bios sobre la base de lo descrito por Philippe Descola en relación con sistemas de pensamiento amazónicos. Este orden contiene otra gramática y otras posiciones que describen el contacto entre lo humano y lo animal, que implica reflexiones ejercidas por medio de una lógica de la alteridad. En esa dimensión, 'conocer es 'personificar', tomar el punto de vista de lo que es preciso conocer. $\mathrm{O}$, más bien, de quien es preciso conocer, porque todo consiste en saber "el quién de las cosas" (Viveiros de Castro, Metafísicas 41). En Metafísicas caníbales, la relación entre las personas, las palabras y las cosas, existe en una mediación recíproca que convoca al sujeto a asumir el lugar de ese saber organizado en un conjunto de interacciones entre seres humanos y no humanos. El narrador del cuento toma posición del lado del jaguar, está en su perspectiva, se vuelve un jaguar en el pueblo de iauretama y su interacción con la naturaleza y la selva describe otra posición de lo humano en este contexto. El sujeto no interviene el entorno, sino que es una parte de esa naturaleza y comprende las relaciones contenidas en ella.

La íntima relación entre el humano y el animal deviene de esa implicación mutua en la que es posible asumir con propiedad las oscilaciones del devenir. Su condición cosmopolítica alcanza

uno de sus puntos culminantes en el asombroso ejercicio perspectivista que es "Mi tío yaguareté", de Guimarães Rosa, la descripción 
minuciosa, clínica, microscópica, del devenir animal de un indio. Devenir animal de un indio, que es también, antes, el devenir indio de un mestizo, su transfiguración étnica por una metamorfosis, una alteración que promueve la desalienación metafísica (Viveiros de Castro, La mirada 93).

Este ejercicio de la alteración y la metamorfosis rearma las particularidades de la forma y la organización del conocimiento, por medio de una promoción del contacto y la proximidad como posibilidad de articular el ser y el saber.

La actividad del conocimiento, en el cuadro cosmopolítico, no se identifica con la noción de la naturaleza como objeto, aquella que establece una continuidad idéntica de lo dado al arbitrio de los roles de sujeto y objeto establecidos de manera excluyente. El sujeto se apropia de un objeto no marcado y plano donde el entorno está subordinado a una racionalidad instrumental. Por el contrario, el narrador del relato se enfrenta a esa dicotomía desde el afecto del jaguar, en que lo natural carga con él una intención, una posición de enunciación, una perspectiva. En consonancia con esta reflexión, las estrategias del pensamiento amerindio en Metafísicas caníbales apuntalan y confirman la condición política, epistémica y cultural de la perspectiva.

Numerosos pueblos del Nuevo Mundo (verosímilmente todos) comparten una concepción según la cual el mundo está compuesto por una multiplicidad de puntos de vista: todos los existentes son centros de intencionalidad, que aprehenden a los otros existentes según sus respectivas características y capacidades (Viveiros de Castro, Metafisicas... 33).

A partir de esta reflexión, las posiciones de quienes existen en el mundo son medidas según su intención bajo un paradigma de lo múltiple y los sujetos están inscritos en ese devenir de la multiplicidad. El saber se inscribe en la concepción de un mundo intenso de relaciones entre las especies, los cazadores, las presas, los jaguares, los humanos, etc. La condición de la perspectiva implica que las posiciones de intención se enfrentan a la racionalidad instrumental que concibe a la naturaleza en una inercia que solo es agitada por la voluntad de saber y dominio del sujeto.

El pensamiento amerindio, en palabras de Viveiros de Castro, se establece por medio de un perspectivismo y un multinaturalismo. De esta manera, las posiciones de los actores dependen de los puntos de vista en que estos se sitúan, en los que se posicionan como personas debido a su capacidad de cargar con una intención, 
Todos los animales y demás componentes del cosmos son intensivamente personas, virtualmente personas; porque cualquiera de ellos puede revelarse como (transformarse en) una persona. No se trata de una simple posibilidad lógica, sino de una potencialidad ontológica. La "personidad" y la "perspectividad" -la capacidad de ocupar un punto de vista- son cuestión de grado, de contexto y de posición, antes que propiedades distintivas de tal o cual especie (Viveiros de Castro, Metafisicas... 37).

El nudo del perspectivismo en el relato de Guimarães Rosa permite la transformación y el devenir del personaje humano, otrora tigrero, vuelto miembro del pueblo de los animales, con ellos se une por medio del parentesco y la creación de una nueva lengua. Su afinidad deviene de su relación con los jaguares basada en el reconocimiento mutuo. Así, en palabras del narrador, los jaguares "[n]o tenían dudas de mí, olfatean que soy su pariente... Eh, el jaguar es mi tío jaguareté" (425). El narrador está en la perspectiva del jaguar, él toma su punto de vista y establece una alianza de parentesco con ellos, conoce su saber y su ontología en la selva, tanto así que los jaguares reconocen al sujeto como miembro de su especie también.

El narrador desafía la norma de las filiaciones y los límites de lo humano. Las características de su origen, como se ha destacado junto con Viveiros de Castro, marcan un devenir indio de un mestizo y un devenir animal de su filiación india. Su lengua es testimonio de esa transformación, como lo hemos señalado en la sección dedicada a la crítica, la desregulación de la gramática expresa el complejo de afectos que atraviesan su lugar de enunciación y sus alianzas de parentesco. "El jaguar es mi pariente, jaguareté, mi pueblo. Mi madre decía, mi madre sabía, ue-ue... El jaguareté es mi tío" (441). De ese modo, el iauaretama -"pueblo/tierra de los jaguares"- es un pueblo por venir, la actualización de una potencia de las alianzas que desregula las ontologías y las identidades fijas por medio de la metamorfosis.

Esta enunciación genera conflictos con la estructura del lenguaje y el gobierno de las identidades, el narrador expresa su vocación por formar un pueblo sobre la base de las tramas del pensamiento amerindio que descubre un complejo inestable de fuerzas, debido a su inscripción humano-animal. Su transformación en curso advierte la formación de un pueblo, la apertura de los límites políticos y ontológicos cuya fundación expresa "la exposición sin fin de los pueblos, entre la amenaza de desaparecer y la vital necesidad de aparecer pese a todo" (Didi-Huberman 222). Esa tensión desindividualizante es la capacidad reveladora de un pueblo jaguar con su fuerza y energía. 
Estas características señalan una filiación entre cultura y naturaleza que designa otra economía del sentido en su devenir animal. Lamentablemente, ese ejercicio de alianzas inesperadas no es sostenible en el relato debido a su desenlace fatal que termina con la muerte del protagonista después de que su huésped se transforma en su verdugo (bajo la paradoja inmunitaria que comporta la oposición del latín entre hospes y hostes: huésped y hostil). Este asesinato abrupto indica el problema antropocéntrico, epistemológico, político y cultural de reconocer aquella metamorfosis, basada en las categorías del pensamiento amerindio según sus epistemologías constantes y ontologías variables.

Esta identidad establecida en el borde, en el filo del contacto, registra el traspaso crítico entre la figura del hombre y del jaguar. No existe una capacidad para traducir esa transformación. Los gestos para señalarla implosionan la gramática y la política humana, generan un plurilingüismo y una nueva política, en ese gesto de exposición de un pueblo nuevo -el pueblo de los jaguares, iauretama- se convierte en una enunciación riesgosa, sus formas de asociación se desmarcan del terreno gobernado por las reglas de la política antropocéntrica y se traspasan esos límites por medio de una enunciación performativa de la lengua y los afectos.

La narración expone la lógica de ese pueblo por venir en su posición de riesgo, insubordinada y trágica, "la belleza de los pueblos es una belleza de resistencia: belleza de sobrevida y sobrevivencia a la vez. Ahora bien, esta búsqueda apasionada no se produciría sin la observación concomitante, o el diagnóstico terrible, de un asesinato de los pueblos en la historia moderna" (Didi-Huberman 206). Este asesinato de los pueblos, su emergencia y su peligro, se condice con el restablecimiento de la identidad y el cierre de la enunciación del narrador al final del cuento, la contradicción y la tensión de la belleza de los pueblos en su sobrevivencia, en su porvenir, y su silencio en el devenir de la historia moderna, donde ante la palabra del pueblo se impone el silencio del Estado y el restablecimiento de una lógica de la identidad fija y homogénea. La recepción del relato por parte del viajero evidencia esa tensión en la diégesis, el huésped restablece el corte entre bíos y zoé con el disparo del arma de fuego que instaura nuevamente las fronteras de lo biopolítico que excluye lo animal de lo humano.

El protagonista y su metamorfosis son eliminados. Su experiencia no es comprensible ni asimilable por el huésped situado ante lo intolerable, su asesinato marca el punto más alto de la mezcla lingüística, “ ¡Mire el jaguar! Ui, ui, usté es bueno, no me haga eso, no me mate... Yo-Macuncozo... No 
haga eso, no lo haga... Ñeñeñén... ¡Heeé!” (454). En este fragmento, asociado a la muerte, en el fin del relato se expone la performatividad del lenguaje en la transformación, donde el tupí, el portugués y la lengua felina son una madeja inasimilable por el viajero. "El narrador no consigue volverse inteligible ante su interlocutor: es puro extrañamiento, opacidad, ruido en la lengua" (Giorgi 60). Esta relación con la muerte es una crisis de la experiencia, el final de la diégesis se impone por la fuerza y el restablecimiento de las condiciones de la gramática de la lengua, el orden y el poder,

[e] o próprio ato de narrar que, operando sobre a linguagem, leva o onceiro a essa inevitável e perigosa metamorfose final. Nessa fronteira, coloca-se em risco o próprio estatuto da narração: não temos mais uma típica "voz narrativa", isto é, uma "voz" que, com maior ou menor onisciência, elabora um discurso sobre algo, mas um texto que, no limite, nem sequer é narrativo: um texto que é só voz, é pura presença de uma voz (Soares 3).

En ese último contacto se estrellan los significantes como materiales que ponen fin a la narración y sellan el cierre de la experiencia del narrador con su muerte. El ingreso de esos materiales, aquella voz, como ruidos, como expresiones desconectadas expresan fuertemente la imposibilidad de seguir con el trabajo de contar. El texto muestra una provocación al poder y la gramática, marca el paso entre la sobrevivencia y el asesinato de la belleza de los pueblos por venir. Esa tensión por la sobrevida es establecida por medio de la desarticulación y la figuración de la voz que violentaba la estructura de la lengua, un sonido que es sepultado en el silencio luego de la muerte del narrador víctima del arma de fuego de su huésped.

El ingreso de la materialidad de la voz marca, como señala Soares, el lugar de lo no representable, la experiencia de cierre, el cese de la fluidez de la trasmisión de la experiencia que señala la metamorfosis como un viaje de ida, pero no de regreso. "El lenguaje del iauaretê es, al final del relato, la prueba de la metamorfosis y, al mismo tiempo, la exposición del vacío dejado por la desmembración del lenguaje, la comprobación de que el lugar de llegada de la transformación es, pese a todo, irrepresentable" (Yelin 226). El cierre abrupto y el desmembramiento del lenguaje son el silencio de la palabra y efecto de la ley, cuyo resguardo inmunitario prevalece en el esquema de la biopolítica ante la relación del humano como animal. Aquí no se lee la constitución de esa identidad como una multiplicidad, sino que hay una condena de la diferencia -la diferencia animal-entendida nuda vida descartable, como 
señala Agamben, restablece el juego de la biopolítica tradicional por medio de la exclusión de aquellos animales que solo producen ruido, aquellos que no son personas y que no tienen palabra que los representa.

\section{CONCLUSIONES}

Este cuento consigna los desafíos de la cosmopolítica sin tener intención de elaborar un programa ni un proyecto positivo, más bien, "[e]l texto de Guimarães verifica y cancela, abre y archiva esa voz y esa comunidad alternativa: narra a la vez su posibilidad y su imposibilidad, y hace de la ficción la instancia de esa ambivalencia" (Giorgi 51), la ambivalencia de la experiencia que se expresa en esta media lengua usa la literatura como el archivo, el registro. La huella que se multiplica en la tensión ejercida al complejo de fuerza antropocéntrico de la cultura y el lenguaje. Por otra parte, en palabras de George Didi-Huberman, este trabajo contribuye a la exposición del pueblo en el momento de su aniquilación, la narración lleva a cabo el trabajo de exponer esa sobrevivencia justamente en el momento de su extinción que muestra el ocaso de su potencia figurativa. Este proceso ocurre por la instalación de la modernización en el sertón, la extinción de formas de vidas diferentes de la explotación de la hacienda, el contacto intenso entre humanos y no humanos en el medio natural se subordina a la lógica de la extracción de recursos e instalación de identidades homogéneas y excluyentes.

Las perspectivas lingüísticas que registran el uso del lenguaje en el texto son un punto de partida para establecer diversas posiciones asociadas con marcos teóricos contemporáneos. La relación con el animal como una apertura del sujeto hacia una alteridad dentro de sí mismo expresa una alianza entre lo humano y lo no humano, expuesta en el vínculo con María-María y el pueblo de los jaguares: iauretama. Esta relación abre el texto hacia el pensamiento amerindio que establece sus relaciones en el ámbito de lo cosmopolítico, como señala Eduardo Viveiros de Castro, Philippe Descola y la metafísica antropofágica, cuya propuesta establece relaciones con la naturaleza sin pasar por una clave antropocéntrica.

La alianza con los parientes jaguares muestra el borde peligroso del humano y la bestia en la formación de un pueblo por venir, en una transformación sin retorno hacia los cambios de los cuerpos y las especies. El archivo de esa transformación inestable consigna la imposibilidad, impotencia y límites del lenguaje para registrar una experiencia de lo múltiple, como señalan Julieta 
Yelin y Erich Soares. En ese gesto, hay una exposición y fuerza de una comunidad alternativa, iauretama, una relación con la palabra y una experiencia inconcebible para ingresar en una gramática estable y normalizada, por lo que, esa nueva alianza disidente, más allá del orden de lo humano, se hace incomprensible. El gesto cosmopolítico se silencia por medio de la muerte del protagonista, pero el relato es un registro de una comunidad imaginada establecida en el cruce de lo animal y lo humano a partir del pensamiento amerindio.

El signo del jaguar, su lengua y su alianza, se sella con la estampa de un fracaso de la comunicación con el interlocutor viajero. Ahí hay una señal de una carencia, una impotencia y una doble marca del exterior; por un lado, el exterior como violencia fuera los límites de lo discursivo sobre lo humano y la política, es decir, una violencia como castigo y la eliminación como exceso de la ley. Por otro, hay un más allá de los límites del discurso, en otro extremo, hay un espacio inestable, intenso y envolvente, en que lo humano es traspasado por lo animal como una multiplicidad simultánea e indistinguible, una metamorfosis, un devenir intenso, un devenir animal.

\section{BIBLIOGRAFÍA}

Agamben, Giorgio. Homo sacer. El poder soberano y la nuda vida. Valencia: Pre-textos, 2006. Cernicchiaro, Ana Carolina. "Antropofagia e perspectivismo: a diferonça caníbal em 'Meu tio o Iauretê"”. Revista Landa, Vol. 3 \#1 (2014): 84-102.

De Campos, Haroldo. “A linguagem de Iauaretê". O Estado de São Paulo, 22/12/1962. 3.

Deleuze, Gilles. Conversaciones 1972-1990. Valencia: Pre-textos, 1996.

"La inmanencia: una vida...". Ensayos sobre biopolítica. Excesos de vida. Compilado por Gabriel Giorgi y Fermín Rodríguez. Buenos Aires: Paidós, 2009. 35-41.

Descola, Philippe. Diversidad de naturalezas, diversidad de culturas. Buenos Aires: Capital intelectual, 2016.

Didi-Huberman, Georges. Pueblos expuestos, pueblos figurantes. Buenos Aires: Manantial, 2014. Garramuño, Florencia. Mundos en común. Buenos Aires: Fondo de Cultura Económica, 2015. Giorgi, Gabriel. Formas comunes. Animalidad, cultura, biopolítica. Buenos Aires: Eterna Cadencia, 2014.

Guimarães Rosa, João. "Meu Tio Jaguareté". Campo general y otros relatos. México D.F.: FCE, 2001.

Imbroisi, Walder y Joyce Scorilack. "Solidão: a linguagem em devir do iauaretê". Macabéa. Revista eletrônica do Netlli 1 (2012): 68-85. 
Lestel, Dominique. "A animalidades, o humanos e as Comunidades Híbridas". Ensaios de zoopoética e biopolítica. Compilado por María Esther Maciel. Florianópolis: Editora da UFSC, 2011. 23-53.

Maciel, Maria Esther. "Paisagens Zooliterárias. Animais na literatura brasileira moderna". Revista de Crítica Literaria Latinoamericana 79 (2014): 265-276.

Núñez García, Amanda. “Gilles Deleuze. Pensar el porvenir”. Daimón. Revista Internacional de Filosofía, Supl. 3 (2010): 107-115.

Perrone, Charles. "Notas para facilitar a leitura de 'Meu Tio o iauaretê'”. Hispania 91, 4 (2008): 765-773.

Reinaldo, Gabriela. "Estômago de ostra -notas sobre o processo tradutores em Haroldo de Campos, Vilém Flusser e Guimarães Rosa". Galáxia. Revista do Programa de PósGraduação em Comunicação e Semiótica 19 (2010): 263-273.

Soares Nogueira, Erich. "A voz indígena em "Meu tio o iauaretê", de Guimarães Rosa”. Nau Literária: crítica e teoría de literaturas. Vol. $9 \mathrm{~N}^{\circ} 1$ (2013). Consultado: 8 septiembre de 2016, en seer.ufrgs.br/NauLiteraria.

Torrano Andrea. "Ontología de la monstruosidad: el cyborg y el monstruo biopolítico". VI Encuentro interdisciplinario de las Ciencias Sociales y Humanas. Universidad Nacional de Córdoba, 2009.

Viveiros de Castro, Eduardo. Metafísicas caníbales. Lineas de antropología postestructural. Buenos Aires: Akal, 2010.

La mirada del jaguar. Introducción al perspectivismo amerindio. Entrevistas. Buenos Aires: Tinta Limón Ediciones, 2013.

Yelin, Julieta. "Viajes a ninguna parte. Sobre la representación de la animalidad en 'Meu teu Ianareté' de Joao Guimarães Rosa y Paixao segundo G.H. de Clarice Lispector". Itinerarios Vol. 8 (2008): 223-233. 